\title{
The Development of Sport and Health Industry in Liaoning Province under the influence of" Health Service Organizations, Family, and Social Collaborative Model"
}

\author{
Yong Zhu', a \\ Department of Physical Education, Shenyang Institute of Engineering, Shenyang, 110136, China \\ aemail,
}

Keywords: Health Service Organizations, Family, Social Collaborative Development, Sports \& Health Organizations

\begin{abstract}
Physical quality enhancement program of average citizens is part of the public health enhancement program, which is a series of processes that focus on maintaining and improving the overall physical quality of the general public. As we all know, there are many factors that affect the health and physical quality of the average citizens. For instance, their daily behaviors, environmental factors, living habits, and the amount of physical exercises taken. This article aims to focus on the research of the collaborative development of the health and sports industries from three core perspectives: health services organizations, family, and the society, and offer advice and solutions to some of the corresponding problems that the health and sports industries are currently suffering from to better serve and push forward the development of universal sports and health industries in Liaoning province.
\end{abstract}

The In-Depth Analysis on the Health Service Organizations, Family and Social Collaborative Development Model

The health organizations, family, and social collaborative development model includes the following aspects and contents.

The Establishment of A Multi-Perspective Content System under the Collaborative Development Model. Under the collaborative development model, all elements can work together to ensure that each of the element can maintain and enhance the physical quality of citizens, promoting their awareness and their habits for physical exercise, and enabling the system to better allocate and applied the proper resources to certain aspects.

The Cooperation and Coordination between Different Elements under the Influence of Collaborative Development Model. Both health service organizations and communities should focus on the physical qualities of service subjects as the core under the collaborative development model to establish citizen health promotion and interference mechanism among family members through scientific propaganda and communications, in order to maximize the value between different social elements.

The Openness and Flexibility of Elements under the Influence of Collaborative Development Model. The collaborative development model is a model, in which health service organizations, families, and the society can adjust their activities and measures of interference to keep emphasize the importance of physical exercises base on the physical status and individual need of average citizens. The goal of health organizations, family, and social collaborative development model is to improve and enhance the body shape, fitness, mentality, sports ability, and the ability to better adapt to the society for citizens in Liaoning province, and apply certain measures to monitor and maintain the processes through health and fitness lessons offered by both health service organizations, families, and communities.

Base on the analysis above, we can draw the conclusion that in order to build a universal sport and 
health service industry in Liaoning province under the guidance of health service organizations, family, and social collaborative development model, a system that contains all the necessary elements and capable of coordinating between them must be built to better boost the steady growth and development of current sports industry in Liaoning province.

\section{The Main Mission of the Health Service Organizations, Family and Social Collaborative Development Model}

The Major Task of the Social Health Service Organizations. The health service organizations are the locations, in which citizens receive health advice and forming the awareness of physical exercises. The majority of citizens do have the appeal or desire to conduct physical exercises after their work, or in their free time. The health and services organizations, on the other hand, play the role of guiding and teaching the general public to conduct physical activities in ways that fit into their personal life styles. The organizations should also provide the basic environments and demands to meet the health demand of average citizens, for they play a key role in monitoring and maintaining the health status of general public. As culture, economy and social-politics evolve, the demand for health and physical exercises of citizens tend to alter in a dynamic pattern. In the meantime, the difference in gender, age, family environment, income level, level of education received, resources available, and personal hobbies also play major roles in the diversity in individual health services demands.

The Major Task of Families. Families are entities that social beings are born into. The major task of families from a physical health perspective is to coordinate with local health services organization to promote and monitor the health developments of their members, especially those of youths. Studies indicates that parents with habits and appeal to participate in physical exercises with their children had a significant influence in motivating their children to conduct physical activities and raising its awareness. Physical health promotion from a family perspective includes family health education, life style management, nutritional diet, and physical activities. Its first mission is to raise citizens' awareness to participation in physical exercises, and then supervise each members of the family to form healthy life style and maintaining the appropriate nutritional diet.

Under the influence of collaborative development model, and the coordination between families, health services organizations and communities, families with atmosphere for physical exercise will certainly motivate family members to help and supervise each other, hence forming virtuous development models within families. On the other hand, acceptability from a family perspective also has a significant impact in pushing forward the collaborative development model, especially on a community health guidance level. The maximum level of coordination on family level also can maintain maximum value of the family itself.

The Major Task of Communities. Social communities play the most common and significant roles in the development of public sports and health industries, for it is where the majority of citizens conduct their daily activities. As citizens' cultural and physical life standard evolved, communities sports event has gradually developed into a major component of sports actives and a major part of sports events for Liaoning province. The promotion of citizen health status from a community perspective includes, conducting all sorts of sports cultural activities, and establishing sports clubs, which forms the atmosphere for physical enhancement and provide the basic sports and health service and insurance for the general public.

\section{Strategy and Advice Public Health Service Organization-Family and Social Collaboration Model}

The Establishment of A 3-Dementional Model Which List Citizen Health Service Organization As the Dominant Force and Family and Community Assistance As Secondary Contribution. During this process, we have to maintain health and service organization has the leading force, and the 
assistance of family and social communities as secondary assistance to better guilt and encourage citizens to participate in physical activities, in order to benefit the long-term development of the health and service industry. For instance, health service organizations can organize public physical activities through the propaganda of physical Science popularization campaign and the introduction of ways to conduct physical exercises. This strategy can not only address the issue of lack of physical exercises among the average citizens due to the lack of time, but also motivate them to participate in physical exercises, which will eventually form a public health promotion and collaboration system based on the public health service organization-family and social collaboration model in Liaoning province.

Offering Physical Health Guidance to Citizens to Raise Overall Level of Physical Exercise of the General Public. Currently, the deterioration of citizen physical quality in Liaoning province has become an unavoidable problem, which was mainly attributed to the decrease in levels of individual physical exercises conducted overall all. Therefore, increasing the average level of physical activities and guiding the general public to conduct physical exercises has become the key to improve the overall citizen health quality and a critical point to establish a quantification guidance model under the collaborative development model.

First and foremost, Liaoning province should utilize all the sports and health service infrastructures and resources available base on the establishment of the collaborative development model, especially those of 2013 National Games, to better guide citizens to conduct physical exercises in more frequent and diverse patterns. Secondly, communities should offer guidance to diversify the forms of physical activities and maintain the appropriate amount of physical exercise taken by average citizens during their casual time, in order to better guide them to participate in physical exercises. Thirdly, establish and promote a casual competitive mechanism based on the community level as the basis to enable citizens to enjoy both competitive and casual sportsmanship during the process.

Perfecting the Service Support Mechanism to Enhance Management and Surveillance under the Social Collaborative Model. The discipline support mechanism, service support mechanism and physical quality monitoring mechanism served as the three major pillars to maintain and improve citizen physical and health quality in Liaoning province. The discipline support mechanism ensures that time for citizens to conduct their daily physical activities, while the service support mechanism serves to provide and maintain the basic infrastructures to conduct these activities. Establish the health service organizations, family, and social service platform in Liaoning province to form a system of management, execution, and monitoring, in order to manage citizen health status on a more comprehensive and steady level and serve to provide service and support for the improvement of citizen health quality in Liaoning province.

\section{Conclusion}

The health and sport service industry of Liaoning province should seek better development opportunity base on fully mobilizing citizens to participate in physical exercises. The health and service organization, family, and social collaborative model is not only an improvement upon the entire health service industry, but also an in-depth enrichment in content for the development of sport industries. Hence, the collaborative development model which base on health and service organization, family, and society as core elements will definitely push forward the development of sport and service industry in Liaoning province.

\section{Acknowledgements}

Achievement of 2017 LiaoNing Provincial Federation Social Science Circles research project: "The Study on the Development of Universal Sports \& Health Service Industry in Liaoning Province"20171slktzd-014 


\section{References}

[1]Liang Li -min, Ye Xiang - cai. Research on the Prospect of Public Leisure Sports Service and its Countermeasures[J].Journal of Guangzhou Physical Education Institute, 2006.11(6):35-39.

[2]Qin Wei, LV Chun-hua, Chen Yu-hua.Life behavior survey and health maintenance of middle aged men in community[J].Journal of Community Medicine, 2008, 6 (5): 43-44

[3]Xiao Lin - peng, Sun Rong - hui. On the Foundations of Physical Health Service System for the Young People in China[J].Journal of Tianjin University of Sport, 2009,24(4):281-284. 